\title{
Reflections on the Environmental Impact Assessment Processes in Turkey
}

\section{Oltan Evcimen}

Erciyes University, Department of Sociology

\begin{abstract}
Environmental Impact Assessment (EIA) process is a procedure that the environmental impacts of decisions on people, fauna and flora, soil, weather, climate, land, cultural heritage, etc. are taken into account before the decisions are made. Moreover, the EIA process has gradually been evolved to cover social aspects. However, Turkish legislation and implementation of EIA process seem to have significant problems when it comes to assessment of decisions on social aspects. This article will offer a critical account on the EIA process in Turkey with regard to the analysis of social impacts. The study will especially focus on whether the EIA reports in Turkey deal with the medium and long-term social impacts of the decisions in real terms and whether these reports have practical benefits in decision making processes. Moreover, the author will specifically ask whether EIA reports in Turkey assess the investments in terms of usefulness and sustainability. The main argument in this study is that those significant merits of the EIA process directly depend on the strength, efficiency and applicability of democratic participation mechanisms.
\end{abstract}

Keywords: Environmental Impact Assessment, Turkey, Social Impact Assessment, Democratic Participation, Sustainability

\section{Introduction}

Environmental Impact Assessment (EIA) process is a procedure that the environmental impacts of decisions on people, fauna and flora, soil, weather, climate, land, cultural heritage, etc. are taken into account before the decisions are made. EIA is a process that has been evolved into its current state almost in the last four decades. There has been a growing interest in environmental issues, which focuses on the notion of sustainability and reaching to goals of economic development by establishing a harmony with environment. This awareness was reflected in legislation as well to regulate different activities in accordance with principles of environmental protection and prevention of associated problems. The role of European Commission in this process is decisive and the EIA process has been a major consequence and realization of this environmental awareness. Although there are many definitions existing in literature, the following definition is operational for our purposes:

EIA is a process, a systematic process that examines the environmental consequences of development actions, in advance. The emphasis, compared with many other mechanisms for environmental protection, is on prevention. Of course, planners have traditionally assessed the impacts of developments on the environment, but invariably not in the systematic, holistic and multidisciplinary way required by EIA (Glasson et al., 2005: 2).

Thus EIA as a systematic and holistic method not only specifies the possible environmental impacts of the projects but also deal with the ways to take measures to prevent these impacts. As Gilpin (2000: 4-5) states EIA not only investigates the "likely effects of a proposed policy, program, or project on the environment" but also it offers "alternatives to the proposal" and "measures to be adopted to protect the environment."

This paper aims to examine the environmental impact assessment processes in Turkey, which are regarded as one of the most effective tools globally in reducing environmental problems. EIA applications in Turkey will be examined in terms of legal processes and difficulties in implementation, and efforts will be made to understand how the EIA process has undergone a major transformation. In this context, one of the main objectives of the study is to explain the link between EIA processes and social factors. The EIA process appears to be a product of a sustainable development framework and a human-focused approach to the concept of ecology. Being also an academician, the author is a social impact assessment expert who has participated in various levels of EIA processes since 2000 in Turkey. Through this experience and 
knowledge, it is examined how stakeholders perceive the problems in relevant legislation and difficulties in implementation in the EIA processes in this study. While addressing the structural problems in the EIA processes in Turkey, the author also examines the social awareness to the environment and the effects that this problem has on the EIA issues, which are as important as these structural problems. The main assumption of the study is that EIA processes in countries such as Turkey where social awareness to environmental problems are mostly perfunctory. In this context, even if the legislation on EIA processes is formulated flawlessly, structural problems arise in the implementation of these processes.

The fact that the EIA processes in Turkey are not developed through adequate environmental awareness does not mean that only the cultural and social structure can be blamed for the deficiencies and problems in the implementation and relevant legislation. Today, many environmental problems are resulted from the fact that policy makers tend to prioritize development in their choices between environment and development. The results of such decisions lead to environmental and social problems cannot be compensated in the future. Waiting for increased environmental awareness in the solution of ecological problems will lead to a number of problems that cannot be solved in the middle and long term. At this point, instead of policies that prioritize development, an understanding based on principles of sustainable environment must become dominant. It is necessary to examine the structure of the perception that is common in member countries of European Union that environmental constraints and individual interests are parallel phenomena. This would enable us to reveal the facts that prevent the formation of such perception in Turkey and to think about which the steps should be taken to form such a perception.

\section{The Basic Principles of EU Environmental Policies}

There is no doubt that for European Union politicians, environmental problems are far more critical than the politicians of neighboring countries who are not members of the Union. The growing awareness of the environment in the EU countries, the increasingly stronger green movement, and the fact that these countries play a leading role in the international arena cause environmental problems to take more place on the public agenda. In member states of the European Union, environmental sensitivities play a decisive role in all political decisions taken about everyday life.

Increasing numbers of disasters such as floods, droughts, forest fires, the increase of carbon dioxide emissions from houses and transportation vehicles, the decrease in quality of life due to pollution and noise especially in urban settlements, and many other environmental problems have become increasingly part of everyday life in Europe as well as other industrialized regions. The fact that the European Union exhibits a minimum of a common political attitude against environmental problems stems from the existence of environmental problems that have become part of everyday life. On the other hand, the cost of eliminating environmental problems threatens the sustainability of economic activities. The most basic condition of economic sustainability has become environmental problems. In this sense, it has become compulsory for the countries of the Union to designate a common environmental policy or to develop a common view towards the environment.

As the scale of all economic sectors such as agriculture, industry, energy, tourism, transportation grows, the environmental problems increase and these problems undermine the economic activities that create them. Today, many researchers are clearly demonstrating a deep relationship between the economy and the environment. However, EU and European countries' policies and awareness towards environmental issues have also evolved from total negligence to an accentuated emphasis on environmental issues. For example, as Jordan (2005: 3) states the word "environment" was not found in the 1957 Treaty of Rome. He maintains that with the increasing environmental awareness in the late 1960s and early 1970s, the member states of European Economic Community have begun to work on environmental issues for better European integration especially in the 1972 United Nations Environment Conference in Stockholm. Consequently, European Commission first prepared the Programme of Action on Environment in 1973. Since then the member countries' emphasis on environment have increased both in terms of legislation and implementation of basic principles.

Although created by environmental sensitivities, the European Union's understanding of sustainable economy and environment is an understanding based entirely on the individual's growing needs and based on economic development. The acceptance of this political point of view by all the member states is primarily due to concern that economic competition should be fair. The environmental problems we face today must undoubtedly be addressed on a global scale beyond the national borders. However, the commonality of the views of the member states of a nuclear activity is related to the fact that the thorium clouds will not require any visa to cross the national borders between France and Britain, as well as a standard in the production costs of energy and creation of a competitive economic space in unity. This partnership does 
not mean only the protection of a cleaner environment and ecological equilibrium, but also the creation of a common and competitive market.

Moreover, the freedom of movement of capital, goods and people is mainly based on fair competition conditions to be provided within the European Union countries. In short, what makes the European Union a political, economic, cultural and environmental union is itself in the conditions of fair competition. In order for different political approaches to environmental problems not to be obstacles to fair competition, it is necessary to create a common environmental policy, common approaches and a social demand to support this policy. Today, the rise of the environmentalist social movements in the European Union countries in parallel with each other is based on a common market understanding as well as a movement to prevent environmental problems. Such a social demand is necessary to legitimize the additional costs that are created by the means to be used to solve environmental problems and which, in the end, must be paid by the citizens. This environmental demand will create common policies within the European Union that will be developed against environmental problems. These common policies, while raising environmental standards, will be the founders of fair competition as well. In short, environmental problems are caused by the unlimited needs of the individual. Individuals created an environmental perception at the point where the environmental problems threatened their daily lives. This perception has made it a political imperative to establish certain environmental standards. These standards ensure fair competition conditions that form the basis of the European Union. We can call this cycle a cycle of environmental awareness and economic interest.

When we look at the basic principles of the EU environmental policy, it is possible to see the cycle we are trying to convey above. The primary principle of the European Union's environmental policy is integration. Within this guideline, sustainable development is only possible with the harmonization of environmental protection measures with all the policies of the European Union. Integration requires that development be within the boundaries where it has not destroyed itself. With the integration principle, the individual is encouraged to make a request to exchange their short-term interests with their longterm interests. As Musu (2008: 3-4) maintains integration principle aims to integrate different dimensions to environmental policy: "legal, administrative, economic, and participatory." He asserts that the main aim of this principle is to "compare different possible instruments so as to use them in the most efficient way." The second principle is preventive principle, and this principle again emerges as one of the basic principles of sustainable development. Economic sustainability is more important than economic profitability in all circumstances. This principle, which aims to prevent environmental problems before they are created, excludes a self-destructive economic understanding. The cost of such exclusion requires citizens to pay the cost or walk in order to be able to see a beautiful landscape. An environmental policy, where everything is made easily accessible, is incompatible with the preventive principle. In order to eat in front of a beautiful landscape, it is necessary to walk or to pay a large amount of money. In both cases, the landscape will be less affected by human factors and preserved. Moreover, the preventive principle calls for ways to make an investment without causing the problem, rather than creating a problem and then solving it. The third principle is precaution principle. Precautionary principle emphasizes the unpredictability of environmental impacts. If there is a suspicion that an activity will have a negative impact on the environment, it aims to prevent the activity, even if it is not scientifically proven. The fourth principle is the "polluter pays" principle. If there is any damage occurred in any economic activity, the responsible party pay the costs of that particular activity. The last principle is the subsidiarity principle. This principle is based on the fact that the service is provided by the institution closest to the public. This principle, which places responsibility on local governments, emphasizes the complementary effect of the European Union. This principle, which states that local governments are responsible for environmental management, emphasizes the link between environmental issues and the social structure. However, this principle is also subject to many criticisms. As Glachant (2001: 13) maintains some interpreters consider this principle as having a weakening effect on EU environmental policy through which the EU's power on the scope of environmental issues could be restricted.

Environmental Impact Assessment processes have been the most basic environmental control agent that these principles have come to life. EIA processes can also be seen as the implementation area of these basic principles within the European Union. Even though these principles live with many agents in everyday life, EIA processes are the main source of these principles. It would be correct to say that these principles have shaped European Union EIA legislation in practice. As Löber (2011: 44) stated EIA has a novel approach to the environmental issues at hand:

EIA ... seek to overcome the vertical approach to environmental issues, i.e. the goal was to integrate environmental policies into other policy fields. They require that environmental issues be considered across all sectors; previously, problem solving 
remained strictly within the borders of the addressed sectors. This vertical policy-style could not consider the environment as a whole, thus measures to solve one problem often had adverse effects on other environmental issues.

Moreover, the prerequisite for these principles to survive in EIA implementation is the public pressure to ensure that these principles are implemented correctly and are included in legislation. In order for this kind of public opinion to be formed within the framework of individual preferences, it is primarily necessary for the individual to develop a medium- and longterm perspective that prioritize environment over development. This is fundamental to determining the legal framework and the effectiveness of the EIA processes.

\section{Some Problems of the EIA Processes in Turkey}

The legal source of EIA processes in Turkey is the EIA directive, which has undergone 17 major and minor changes from 1993 to 2017 in total. According to a statement made by the Chamber of Environmental Engineers, the ElA directive, published in the European Union in 1985, has only been amended three times. This can even be seen as a proof of the perfunctory nature of the EIA processes in Turkey, which inevitably generates the lack of interest in fighting environmental problems and in environmental protection. When the concept of EIA first emerges in Turkey, it can be seen that the legal regulations in this area are far from aiming to balance the environment and the economy and to realize the basic principles we consider above. EIA first entered environmental legislation in August 1983 with Article 10 of the Environmental Law No. 2872. However, the EIA Regulation has been published only after 7 February 1993, almost 10 years later in various negligence and delays. With the provisional Article 3 of the first published Directive, the projects for which approval, license, permit, and expropriation decisions were taken before the enactment of EIA Regulation of February 1993 were exempted from the EIA process. A legal gap has been created for this 10-year delay: The projects of which the implementation projects have been approved, or a permit, license or approval or expropriation decision has been taken from competent authorities in accordance with the Environmental Legislation and other relevant legislation (or has been selected in accordance with the relevant legislation, activities taken) prior to 7 February 1993 were exempted from the EIA process.

Furthermore, when we look at the amendments made in the directive over the years, it is possible to say that the EIA directive has gradually moved away from the five principles we have listed above. The results of policies by political governments that make the EIA process an "obstacle" in front of the investor and interpret the environmental protectionuse balance by prioritizing "use" principle are also consistent with the EIA statistics of the Ministry of Environment and Urbanization. The number of projects evaluated between 1993-2012, which had positive EIA decision was 2,792. The number of projects for which the EIA is not required decision is 39,649. The number of projects which had negative EIA decision is only 32 . In this sense, the EIA processes have ceased to be processes that will provide the basic conditions of a sustainable ecology and a sustainable economy that will balance ecology and economy in both practical and legal senses. This is confirmed by the European Union official report of 2016 (European Union, 2016). Moreover as many commentators point out, there are important problems related with the qualifications of the people and establishments that prepare EIA reports in Turkey (2010: 132). There are also many shortcomings in the preparation of the EIA reports which conflict with the requirements and methodology of the EIA process. As Ürker (2012: 73) states Environmental Consultancy companies, especially those who prepare EIA reports and complete the related procedures, can prepare reports in a very short time with the encouraging of the related ministries, by copy paste plagiarism without even seeing the project area. The Ministry of Environment and Urbanization, which has the authority to supervise and make decisions about the relevant processes and reports, encourages the urgent realization of the projects rather than putting emphasis on the issue of the protection of environment.

Showing many indications of the imbalance between economy and ecology, Turkey has recently become one of the countries increasing the rate of pollution the fastest, while attaining high figures in terms of economic indicators. However, this phenomenon cannot be said to increase environmental awareness. The number of individuals in Turkey who have to make a choice between economy and ecology and prioritize ecological concerns is very limited. Such inquiries are widespread among environmental groups that are marginalized by the vast majority of the population. The problems arising from the fact that natural equilibrium is sacrificed to economic growth have been concern only to a limited number of environmentalists, sensitive groups, experts, etc. The reasons for this situation is populist policies as well as excessive specialization in the academy and the fact that Turkey does not have a economic and social structure enough to support strong environmentalist political attitude. It is not possible to talk about a strong environmentalist movement or a formation that will bring ecological problems to the public agenda in Turkey. Though there are small local groups that sometimes take a stand against specific projects, they cannot form a national agenda in general, or the national level of environmental 
awareness they have created is very short. It is possible to relate these irresponsibility or lack of interest in ecological problems to many factors in Turkish society. However, the most fundamental of these is the fact that due to high level of economic development differences between regions, ecological awareness cannot take precedence over concerns of economic development. According to the results of Kadir Has University Social-Political Trends Survey held in 2016, Turkey's biggest problem is seen as terrorism. ${ }^{1}$ Unemployment and high cost of living are also at the top of the problems that are seen as important. Interestingly, environmental problems have not even taken place as a category in this research. Even this observation reveals the inadequacy of environmental awareness in the Turkish society. In addition, 71.7 percent of the respondents said that there was an economic crisis in Turkey. According to a research conducted by the Konsensus research company in 2017, ${ }^{2}$ the percentage of respondents who regarded environmental problems as one of the most fundamental problems of Turkey is only $2 \%$, and thus environmental problems seem to be the least important problems. Again in the same survey, unemployment is second with $40 \%$, inequality in income distribution is fourth with a $23 \%$ and inflation / life cost is fifth with $21 \%$.

These numbers suggest that when there are problems that are seen more vital by the society, a sufficient level of environmental awareness is not possible. In 1972 Stockholm Human Environment Conference, Indira Gandhi voiced a similar statement: "There are grave misgivings that the discussion on ecology may be designed to distract attention from the problems of war and poverty". And she continues: "Are not poverty and need the greatest polluters?"3 On October 30, 1984, a statement by the Minister of Culture and Tourism of the Republic of Turkey defended the same view: "Thinking about environmental problems to us is like necktie to a porter. Foreign experts say that if your income per capita is not at least \$ 7-8 thousand, thinking about environmental pollution is a luxury for you". ${ }^{4}$ Since 1972 , it is not hard to predict that the biggest problem in India is still poverty. However, for Turkey, where per capita income is close to 10,000 dollars, it is not understandable that concern for environmental problems is still seen as luxury. In the last 33 years, we are still observing that environmental sensitivities are not sufficient in Turkey. In a country that is late in the process of industrialization and urbanization and having difficulties in the functioning of its political system, it can be seen natural that ecological problems are not regarded as one of the main problems. But this will inevitably lead to worrying problems in the long run. Duru (2013: 5) mentions the relationship between urbanization and the development of environmental awareness:

There are important links between the fact that we are late in the urbanization process ... and the underdevelopment of green movement in our country. From this point of view, it can be suggested that the problems arising from the coexistence of a large number of people in a small space recently begin to emerge. Topics such as traffic, garbage are only a problem on the agenda of one or two latest generations. In short, late emergence of such problems might be said to cause the delay in taking common action for solution and the emergence of strong environmentalist movements.

Thus, as many commentator states, "environmental concern is related to personal memory." (Hussey and Thompson, 2000: 3) The delayed urbanization and industrialization in Turkey has caused the rural to be always remembered with backwardness and the identification of industrial investments, bridges, dams and many urban facilities with modernity and development. This perception hinders the development of environmental consciousness that questions urban facilities in the long run. In Turkey, the analysis of the politicians' responses to the groups that oppose the projects that may cause environmental problems, or bring these projects to the public agenda is very illuminating. These responses are also an expression of the late urbanized and industrialized Turkish society, longing for cities with large, wide streets. It is not possible to expect children of a generation who used to live in villages without roads, carry patients to the hospitals on their back, work in candle light to show ecological awareness to a gigantic hydroelectric power plant or a major highway project This perception of backwardness in Turkish society leads to the definition of EIA processes as meaningless and useless by the individuals.

\section{Conclusion}

The basic condition for the realization of European Union's five basic principles of EIA processes is the change of the individual's view of environmental problems. Unless the environmental demands of the individual are expressible, it seems very difficult to realize these five basic principles in both legal sense and practical sense. Increasing the awareness of

\footnotetext{
1 http://www.khas.edu.tr/news/1498

2 http://www.konsensus.com.tr/turkiyenin-en-onemli-sorunlari/

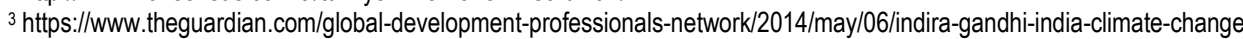

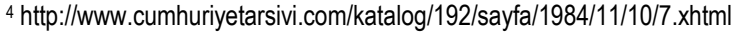


individuals to environmental problems is the most fundamental condition that will bring EIA processes in Turkey out of its perfunctory state. Individuals' environmental demands will be both a challenging element for politicians, and create a basis for an environmental rationality for the private sector. Individuals involved in EIA processes and involved in these processes as an element of resistance with ecological sensitivities will lead the private sector to gain an environmental rationality. One or several EIA reports that are canceled as a result of social reactions would ensure that both political decision-makers and the private sector gain environmental awareness. In order to make people with medium- and long-term concerns for environment effective in EIA processes, it is necessary for environmental groups in Turkey to work on the current social problems of today and develop an approach dealing with local needs, not global ones. However, as we stressed earlier, due to Turkey's unique structural problems, explaining EIA processes solely through environmental issues or the protection of nature will make it difficult for individuals to adopt the principles of the process.

Participation in the EIA processes will increase as the EIA process is linked to the individual's daily life. Defining EIA processes as a solution to more local, more familiar problems such as poverty, shelter, and drought, instead of a distant, foreign issue, where people do not feel individual impacts, such as climate change would make the process more efficient and understandable for people. It can be said that nuclear power plant projects, urban transformation implementations, hydroelectric power plant constructions and mine exploration activities are increasingly faced with more social resistance in recent years in Turkey. But this reaction is far from being an expression of a general ecological resistance. It is clear that main concern of people who have taken action against the construction, mining and energy investments is more the damage to their vital sources and the intervention to their living spaces rather than the environmental problems associated with these projects. Similarly, the basic reason for the increasing involvement of the local people and the villagers in the EIA processes in recent years is also related with their more practical needs. The question of whether it is possible to create an individual that emphasizes ecological concerns from such resistance is an important question. The best way for making the citizens to understand that it is also economically beneficial to deal with ecological problems, even if not in the short run, is to make the EIA processes compatible with the five basic principles of the European Union.

\section{References}

[1] Dervişoğlu, Suat (2011). "AB Müktesebatına Uyum Sürecinde Çevresel Etki Değerlendirmesi (ÇED)." Türk Idare Dergisi 467: 115-134.

[2] Duru, Bülent (2013) “Türkiye'de Yeşiller Hareketinin ‘Sürdürülebilirliği'”. Perspectives 3: 4-7.

[3] European Union (2016). Commission Staff Working Document: Turkey 2016 Report. Brussels.

[4] Gilpin, Alan (2000). Environmental Impact Assessment: Cutting Edge for the Twenty-First Century. Hong Kong: Cambridge University Press.

[5] Glachant, Matthieu (2008). "The Implementation of the Environmental Policy in the European Union Context." In Implementing European Environmental Policy: The Impacts of Directives in the Member States, ed. Matthieu Glachant. Cheltenham, UK: Edward Elgar.

[6] Glasson, John, Therivel, Riki, and Chadwick, Andrew (2005). Introduction to Environmental Impact Assessment. London and New York: Routledge.

[7] Hussey, Stephen and Paul, Thompson (2000). The Roots of Environmental Consciousness. London and New York: Routledge.

[8] Jordan, Andrew (2005). Environmental Policy in the European Union: Actors, Institutions and Processes. London: Earthscan.

[9] Löber, Sonja (2011). "The Place of Knowledge in Policy-Making Processes: An Assessment of Three EU Environmental Policy Instruments." In Sustainability of European Environmental Policy: Challenges of Governance and Knowledge, eds. Rob Atkinson, Georgios Terizakis, and Karsten Zimmerman. London and New York: Routledge.

[10] Musu, Ignazio (2008). "Integrated Environmental Policy in the European Union." In Sustainable Development and Environmental Management: Experiences and Case Studies, eds. Corrado Clini, Ignazio Musu, and Maria L. Gullino. Dordrecht: Springer.

[11] Ürker, Okan (2012). "Türkiye'de Hidroelektrik Santraller'in Durumu (HES'ler) ve Çevre Politikaları Bağlamında Değerlendirilmesi." Ankara Üniversitesi Sosyal Bilimler Enstitüsü Dergisi 3(2): 65-88. 